\title{
The Role and Influence of 'Champions' in a Community-based Lifestyle Risk Modification program
}

\author{
S. Aoun, S. Shahid, L. Le, T. Packer
}

RUNNING TITLE: Champions in a lifestyle risk modification program

\section{KEYWORDS}

The Waist Disposal Challenge, natural helper intervention, Lay Health Advisors, Champions, health promotion, BMI, nutrition, physical activity.

\begin{abstract}
This article describes the training and implementation of the Waist Disposal Challenge in service clubs in Western Australia in 2009-10. Ninety-three Champions from 52 clubs were trained to deliver educational presentations to 1100 peers and facilitate a BMI Competition among 764 peers. Champions reported significant improvements in their knowledge and confidence to motivate their peers to make changes to their diet and physical activity with $82 \%$ of participants completing the BMI Competition and on average $58 \%$ experiencing and sustained a BMI reduction for 12 months. It is evident that the Champions had influenced the uptake and success of the intervention.
\end{abstract}




\section{INTRODUCTION AND BACKGROUND}

Obesity and the related chronic diseases are a major public health issue worldwide. Hence strategies that lead to positive and long lasting lifestyle changes continue to be a major international focus (Commonwealth of Australia, 2008; Eakin, Lawler, Vandelanotte, \& Owen, 2007; Foster, Taylor, Eldridge, Ramsay, \& Griffiths, 2008; VanWormer \& Boucher, 2004). Over the last few decades, many public health services have adopted a proactive, multi-disciplinary self-care model with increased emphasis on prevention and management of chronic diseases. There is growing recognition of the importance of enabling and utilising community resources and support systems and building partnerships with community stakeholders (Eng, Rhodes, \& Parker, 2009; Foster, et al., 2008). Interventions led by Lay Health Advisors (LHA) have gathered increasing recognition as an effective strategy for health promotion, disease prevention and chronic disease self-management at the community level (Fleury, Keller, Perez, \& Lee, 2009; Lorig, Hurwicz, Sobel, Hobbs, \& Ritter, 2005; Quinn \& McNabb, 2001; Rhodes, Foley, Zometa, \& Bloom, 2007).

Middle aged to older men, particularly those living in rural areas, are recognised as a hard-toreach population with health promotion efforts (Aoun, Donovan, Johnson, \& Egger, 2002; Aoun \& Johnson, 2002). One in four participants in a study conducted in rural Australia cared little about their body size and appearance reporting the sentiment that everyone will 'die of something, so they might as well enjoy what they are eating'; and 20\% held the view that 'being physically big for a man has its advantages'(O'Kane, Craig, Black, \& Sutherland, 2008). Men perform more poorly than female counterparts on most indices of health. They live an average of five years less than women, experience disproportionately higher morbidity rates, and have higher levels of disease risk and higher rates of chronic illnesses (Buckley \& Lower, 2002; Egger, 2000; Smith, Braunack-Mayer, \& Wittert, 2006). However, there is little evidence of community-based programs that targeted this population group in the research literature.

LHA-based models recognise that LHAs are "insiders" to their own communities and possess deep understanding of the community's internal mechanisms, strengths, weaknesses and needs (Eng, et al., 2009); they build on community resources and strengths (Debate \& Plescia, 2004-2005) and promote naturally existing social support systems and community ownership. LHAs serve as peer role models and help to make interventions cost effective (Lorig, et al., 2005; Quinn \& McNabb, 2001). Without formal qualifications as health care professionals, they are trained to provide information and support and to motivate their community partners or peers. These interventions offer a powerful means of addressing health-related attitudes, beliefs, and social norms within a social network, particularly for hard-to-reach population groups (Fleury, et al., 2009). The role of LHAs can be multi-faceted: they serve as a liaison between community members and providers; promote community advocacy and capacity building; provide cultural mediation, counselling, social support and culturally appropriate health education; promote attendance at appointments and adherence to medication and other medical regimens and promote delivery of direct health care services (Andrews, Felton, Wewers, \& Heath, 2004; Fleury, et al., 2009). 
Successful implementation of the LHA-based interventions has been reported. Examples include a workplace based study that resulted in improved nutrition and physical activity behaviours among female blue-collar employees in North Carolina (Campbell et al., 2002) and an LHA-delivered program that resulted in a mean weight loss of 8.3 pounds in African American female participants (Quinn \& McNabb, 2001). Moreover, a qualitative systematic review on LHA interventions among Hispanics/ Latinos found that LHAs successfully served as traditional health advisors, offered advice and guidance on a narrowly defined health focus and referred community members to accessible services (Rhodes, et al., 2007).

A LHA-based health promotion intervention, named 'The 'Waist' Disposal Challenge that involved middle aged to older men at a service club setting is described here.

\section{The Intervention: The 'Waist' Disposal Challenge (WDC)}

This intervention was implemented at the community level via Rotary clubs in Western Australia (WA) (Aoun, Osseiran-Moisson, Collins, Newton, \& Newton, 2009). The WDC intervention was designed using the "Natural Helper Intervention Model", a model that guides interventions using lay individuals from communities called "natural helpers" or "lay health advisors" to bring about behavioural, organisational, community and social changes (Eng, et al., 2009).

Middle aged and older overweight or obese men at risk of developing chronic diseases such as diabetes and heart disease were the target population in these clubs. The WDC is comprised of three levels:

Level 1: educational presentations by LHAs (which we called "Champions") on nutrition, exercise and other healthy lifestyle habits to raise awareness of lifestyle risk factors for chronic diseases and the benefits of healthy diet and physical activity. Although "Champions" and "Lay Health Advisors" are described differently in the literature, we decided to use the term "Champion" as it was more appealing to the population group, although the role is similar to that of the LHA's.

Level 2: a Body Mass Index (BMI) Challenge between clubs, facilitated by club Champions. Rotarians with BMI 25 and over participated at this level. Competition between clubs (monthly weigh-ins) acted as an incentive; the club that achieved the largest mean reduction in BMI was awarded "the 'Waist' Disposal Trophy".

Level 3: an individual and personalised telephone Lifestyle Coaching program with regular follow-up offered to Rotarians with BMI 27 and over.

The conceptual approach at the basis of the three levels of intervention in the Waist Disposal Challenge is The Transtheoretical Model which explains the different stages of change common to most behaviour change processes (Nutbeam \& Harris, 1998; Zimmerman, Olsen, $\&$ Bosworth, 2000). As illustrated in Figure 1, education (Level 1) can raise awareness of health issues and foster recognition of the benefits of change, particularly for those in the precontemplation change where there is no intention to change. The BMI competition (Level 2) can move participants from thinking of change (contemplation) to ready for change while individual lifestyle coaching (Level 3) can help people to identify barriers to change and to 
determine an action plan for change. Thus the program helps people to move through the 5 different stages of change by employing strategies effective for every stage.

[FIGURE 1 HERE]

The WDC was successfully piloted in 23 clubs in WA in 2007-08 (Aoun, et al., 2009) . Further funding was obtained to train LHAs from Rotary clubs and to roll out Levels 1 and 2 of the program to all interested clubs in WA between June 2009 and May 2010. Fifty-two clubs participated in the program and 93 Champions were trained to build capacity from within the clubs. A brief one-day training program was developed to suit club Champions. The training of Champions and the implementation of levels 1 and 2 of the intervention are described in this paper. Level 3 implementation is pending further funding. However the pilot lifestyle coaching results were published in Aoun, Osseiran-Moisson, Shahid, Howat, \& O'Connor, (2011). Feedback from Champions on their training and feedback from peers on sessions provided to them by the Champions are also reported as is the key health outcome, i.e., the weight change, achieved as a result of the project.

\section{METHODOLOGY}

The methods used to implement the intervention and to evaluate the procedures and outcomes are described below.

\section{Participants}

Rotarians are mainly business and professional leaders who provide humanitarian service, and belong to clubs which are grouped into districts through the international organization (Rotary International, 2011). The membership is relatively stable; $85 \%$ are male in WA.

Recruitment of Champions: The goal was to recruit and enrol half of the 102 existing WA clubs each identifying two Champions (100 Champions from 50 Rotary Clubs). An initial email, then a follow-up letter was sent to all Rotary Clubs in WA inviting them to participate by nominating one or two members to be Champions for their clubs. Clubs not responding after two to three weeks were telephoned or sent a reminder email. Additional advertisements were placed in District newsletters and in club weekly bulletins; written information was distributed during the District Governors' visits to the clubs; and presentations from the project team were given at club meetings and at the Rotary Annual District Conference. No payment or any other remuneration was offered to Champions.

Recruitment of Club Members: Club members interested to participate in the monthly weigh-ins were recruited by the Champions. The main criterion for inclusion was a commitment to the weigh-ins for a twelve-month period.

\section{Intervention}

The WDC Champion Training Program: The goal of the one-day (9am-5pm) training program was to provide Champions with the skills and resources required to implement the strategies of the WDC, that is, to deliver three educational presentations to their clubs, to provide peer support and motivation; and to conduct the monthly weigh-ins for the BMI 
competition accurately. The WDC Champion Training program was based on the principles of adult learning (Knowles, 1984). Adult learners attend training programs equipped with a wealth of knowledge, experience and skills. They are internally motivated, self-directed, goal orientated and seek training that is practical and relevant. The training program expanded upon and reinforced the existing skills and experience of participants.

The Champion Training program was delivered in four urban locations and one rural location of WA over a two-month period by six health professionals with backgrounds in physiotherapy, exercise physiology, nutrition, public health and health promotion. Activities included lectures, hands-on practice, observations, group discussions and role play delivered using both learning and facilitation principles. The training program consisted of five modules:

i. Overview of the 'Waist' Disposal Challenge - Fighting risk factors for chronic diseases

ii. Being a Champion - 'The new idea either finds a Champion or dies'

iii. Running the BMI Competition in your Club

iv. Nutrition to Assist your 'Waist' Disposal - You are what you eat!

v. Physical Activity Session - Move it, or lose it!

Each Champion received a resource folder of educational materials. A WDC certificate was given after completion of the training, providing a sense of legitimacy and importance in becoming a 'WDC Lifestyle Champion'. The emphasis was on the delivery of information and activities included in program, allowing Champions to move from being a passive leader to becoming a recognised 'health advisor' amongst their peers. An Action Planning Worksheet served as a tool for Champions to assist club members with problem solving and setting goals.

The Presentations on Nutrition and Physical Activity: The structured educational presentations were designed by the WDC team in consultation with the health professionals. These sessions aimed to increase knowledge and awareness about: 1) exercise, nutrition, obesity, and their effect on overall health and well-being; and 2) chronic disease selfmanagement. Each presentation was tailored to be delivered by a lay person, and aimed to be suitable for middle-aged men with no background in health and with limited educational qualifications. Structured PowerPoint presentations were prepared for the Champions to help them deliver their educational sessions to their clubs and also to ensure that the same level of information can be delivered to all participants. Each PowerPoint slide was provided with notes to explain relevant concepts and theories, minimising the use of academic and scientific jargon. A variety of visual tools such as fat model replicas, arterial wall models, pictures of food with fat/sugar teaspoons and exercise photos were used throughout the presentations, allowing Rotarians to connect the information with a visual representation of various health knowledge and messages.

The BMI Competition and the WDC Website: BMI has been shown to be a sufficiently reliable measurement when undertaken by lay people in community settings (Dhaliwal, Howat, Bejoy, \& Welborn, 2010) which was confirmed in the pilot study (Aoun, et al., 2009). 
Guidelines for measuring height and weight, as well as recording BMI data were provided in the resource folder, to take home after the training. All Champions were trained to and practised measuring height and weight at the time of training as per existing protocols and guidelines for measuring height, weight and BMI. Each club was provided with the same set of scales (digital glass scale with maximum limit of $150 \mathrm{~kg}$ ), height measuring devices and a BMI chart (showing the ideal weight for height). Using project equipment ensured the legitimacy of taking formal and regular measurements. Participants were weighed without shoes, jackets, keys and coins in their pockets. Furthermore, the research team was available for any support needed by the clubs either by phone or by visiting them.

A WDC website (www.waistdisposalchallenge.com.au) was developed upon demand from Champions attending the training to increase the spread of information, interest and knowledge amongst Rotarians and their communities. Champions were trained to enter their club's data on-line. There is a section that requires user login and is password protected. This allowed Champions to log in securely and input month-to-month data from the BMI Challenge. As soon as the data were entered, the research officer was notified by an automated email. She then checked data entry and approved it. If anything seemed misleading, she contacted the Champion to clarify and correct the information. All other participating Rotarians were able to log in to see the 'Leader board' information. The leader board is a monthly compilation of all participating clubs which ranks clubs in order from the highest percentage of BMI change to the lowest.

\section{Evaluation}

The WDC was evaluated on three program components: evaluation of the Champion Training Program by Champions; evaluation of the Champions' delivery of the educational sessions by club members or peers; and evaluation of the outcome of the BMI Competition.

\section{The Champion Training Program}

Self-report, pre- and post-training questionnaires in the form of a 5-item Likert-scale (from $1=$ very good to $5=$ very poor) was used to assess Champions' understanding and knowledge of the different program components and their confidence to implement the WDC in their clubs. The pre-training questionnaire included extra questions on demographic information from Champions including roles in their clubs and reasons for volunteering to be a Champion. The post-training questionnaire included extra questions in the form of a 5-item Likert-scale (from1=strongly agree to $5=$ strongly disagree) to assess Champions' satisfaction with the overall training program.

\section{Delivery of the Educational Presentations by Champions}

Brief evaluation questionnaires, developed for each of the three presentations, were distributed by Champions to their peers immediately following their presentations. Anonymous feedback was sought regarding how interesting the content on a scale of 1 to 5 (from $1=$ not interesting to $5=$ very interesting), whether the presentation increased their awareness of what they could do to lose weight, and how motivated they felt to make changes as a result of the educational sessions on a scale of 3 (very much, partial, not at all). 


\section{The BMI Competition}

Impact and effectiveness of the training was measured by the results of the BMI Competition through the collection of monthly data on weight change of club members. The WDC team checked for data consistency and accuracy and trends at the individual and club levels on a monthly basis for a period of 12 months and presented results on the monthly leader board.

\section{Analysis}

Analyses of the data from the three components of the evaluation included standard descriptive statistics, independent and paired Student's $t$-tests, and two-way repeated measures (group x time) analysis of variance. All tests were two-tailed and an alpha level of 0.05 set as the criterion for statistical significance. SPSS $17+$ was used to analyse data.

\section{RESULTS}

\section{Response Rate}

A total of 106 Champions from 54 Clubs enrolled in the training program. Prior to training, attrition occurred due to timing of sessions and other personal circumstances of participants. As a result, 93 Champions from 52 Clubs completed the training (with a total membership of 1100 club peers). Approximately one-third of the clubs were from rural areas. Champions from six clubs did not implement the WDC upon returning from training owing to lack of support from their clubs and personal reasons such as increased work commitments or withdrawing from Rotary. Therefore a total of 44 clubs implemented the program (an attrition rate of 15\%) of which eight implemented only level 1 (educational sessions) and 36 implemented levels 1 and 2 (educational sessions and the BMI Competition) leading to a completion rate for both levels 1 and 2 of $82 \%$.

\section{Profile of Trained Champions}

Seventy percent of Champions were male and the average age was 55.2 years [SD=10.1] (range 25-73 years); Champions had spent a median of five years (range 0.4 -37 years) in their own Rotary Clubs. Seventy percent of Champions held a leadership role in their clubs: $21 \%$ were Presidents, 21\% Directors, 14\% Committee Members and 15\% had other roles at the club level. The majority of Champions had a high level of education with $54 \%$ having completed a university degree and $31 \%$ with vocational or other diplomas. Over threequarters of Champions were employed coming from a range of occupational backgrounds including managerial positions (23\%), farming and trades (12\%), health and community services $(11 \%)$ and education $(9 \%)$. The rest were in finance and insurance, property and business services and communication and technology services.

Champions were asked to provide one or more reasons on a list of seven items for volunteering as a Champion for their clubs. Two-thirds responded, I believe in the importance of prevention in health. Other reasons included: I feel that I can influence my club members (36\%); I have an interest in providing support and information (35\%); I have a specific health condition (32\%); I was asked by the club to take on this role (22\%). 


\section{Evaluation of the Training Program by Champions}

Table 1 compares the pre- and post-training reported change in Champions' knowledge and confidence with regard to chronic disease self-management, healthy diet and physical activity. The data show that the training significantly enhanced the Champions' knowledge and confidence in facilitating the intervention and delivering the WDC presentations in their clubs.

\section{[TABLE 1 HERE]}

Feedback on the content and delivery of the WDC Champion's Training program was also collected post-training. Overall 95\% Champions agreed that the objectives of the training were clear; $97 \%$ found the training content to be appropriate to the objectives. Almost all Champions found the content to be interesting (60\% strongly agree, 38\% agree) and felt prepared to support their club members in adopting healthier lifestyles as a result of the WDC training (44\% strongly agree, $48 \%$ agree). The majority of Champions were able to cope with the amount of content delivered in the training program (53\% strongly agree, $44 \%$ agree). Overall Champions found the facilitators to have presented the information well (72\% strongly agree, 26\% agree) and they were interesting to listen to (73\% strongly agree, $25 \%$ agree).

\section{Evaluation of the three Educational Presentations by club members}

In total, 42 clubs received the Overview presentation from their Champions, 32 the Nutrition presentation and 31 the Exercise presentation (Table 2). Between 52\% and 69\% of the club members or peers returned the anonymous evaluation questionnaire (coordinated by the Champion). The WDC overview presentation was rated on interest at an average of 4.34 (out of a maximum of 5); The Nutrition presentation was rated on interest as 4.23 and the Exercise presentation was rated 4.43. Table 2 presents the positive effect of the 3 presentations on awareness, knowledge and motivation of club members.

[TABLE 2 HERE]

Feedback from club members on the presentations conducted by health professionals in the pilot study (2007-08) and those conducted by Champions in this larger study revealed that the Champions performed equally well if not better than health professionals motivating their peers to make changes to their diet (51\% for Champion-led vs. $38 \%$ for Health Professionalled, $\mathrm{p}<0.001$ ) and/or increase their physical activity ( $56 \%$ for Champion-led vs. $43 \%$ for Health Professional-led, p<0.001) (S. Aoun \& Le, 2010; S. Aoun, et al., 2009).

\section{Impact of the Training: Results of the BMI Competition}

On average, $70 \%$ of club members participated in the BMI competition. Overall, $86.3 \%$ of participants were overweight or obese at the start of the BMI Competition. Thirty-six clubs (764 Rotarians) participated regularly in the BMI Competition. Table 3 and Figure 2 present the weight loss in Rotary Clubs for at least 12 months. A summary of results follows:

1. The BMI Competition was highly successful with an $82 \%$ completion rate;

2. 36 clubs achieved a total weight loss of $757.4 \mathrm{~kg}$, with an average of $57.6 \%$ (range $23.8 \%$ to $91.6 \%$ ) of members having lost some weight. 
3. The largest individual losses within the first 6 months of the competition were $27.3 \mathrm{~kg}$ followed by $16.0 \mathrm{~kg}$;

4. 1 Club had over $90 \%$ of their members lose weight, 2 clubs had $80-89.9 \%$ of their club lose weight, 9 clubs had 70-79.9\% of their club lose weight, 6 clubs between 60 $69.9 \%$, and 6 clubs between $50-59.9 \%$;

5. 16 clubs showed significant reductions in $\mathrm{BMI}(\mathrm{P}<0.01)$, with another 17 clubs showing BMI reductions although not statistically significant, and only 3 clubs had a slight increase;

6. Clubs achieved an average $1.07 \%$ decrease in their BMI $(\mathrm{p}=0.005)$, though 6 clubs achieved over $2 \%$ change ( $p<0.0001$ to $p<0.05)$ with one club achieving a $3.06 \%$ $(\mathrm{p}=0.005)$ decrease in BMI.

7. The trend in the graph shows that during the funded period of the project (Oct 09 to May 10) the BMI reductions were greater and then a plateau happened although the losses were sustained and there was no return to the starting higher BMI levels;

[FIGURE 2 and TABLE 3 HERE]

\section{DISCUSSION AND CONCLUSIONS}

The Champions or LHAs provided an avenue to access a hard-to-reach population group and were able to successfully implement a lifestyle risk modification program. Champions' positive ratings of the content and format of the brief Champion Training program and the significant improvement in their knowledge, confidence and skills (measured before and after the training) were encouraging.

The evaluations received from Rotarians following the presentations by Champions were highly positive. This further confirms that the training was effective in equipping the Champions to deliver health messages in a credible way. Such results also confirmed the initial assumption that club members would relate to having a peer act as a Champion and a health resource for their clubs. This finding resonates with other studies reporting that living amongst the community helped LHAs to be trusted and made people feel confident to turn to them for help (Daniels, Zyl H, Clarke, Dick, \& Johansson, 2005).

Consistent with similar studies (Daniels, et al., 2005; Quinn \& McNabb, 2001), the training was not designed to be intensive, nor did it aim for Champions to become content experts. Delivery and transfer of knowledge to their peers was the main training objective. A very intensive training structure implemented by Brown and colleagues (2007) was deemed not effective in motivating LHAs. Participants referred to the training as 'too demanding', overwhelming, 'dispersed' and as creating a 'fear' of being overburdened (Brown, Hennings, Caress, \& Partridge, 2007). Jackson and Parks (1997) also demonstrated that training of most African American LHA programs consisted of disease-specific content and focused less on interpersonal communication skills and in some instances it was not suitable for targeted population groups (Jackson \& Parks, 1997). It is also crucial to ensure that LHAs have similar backgrounds to other participants (Vissman et al., 2009). By adhering to these principles, the WDC training was very focused and structured on the program goal (BMI reduction) which was measurable and explicit. 
Using the BMI Competition to collect monthly data on Rotarians' weight loss and to track progress through a leader board provided a unique way to evaluate outcomes, unlike previous studies which used less focused approaches (Richert, Webb, Morse, O'Toole, \& Brownson, 2007). The BMI Competition experienced a greater reduction in BMI than that achieved within the duration of the pilot study where no Champions were involved (Aoun, Le, Osseiran-Moisson, \& Packer, July 2009; Aoun, et al., 2009). The literature has emphasized the importance of rewards in maintaining motivation (Avenell, Satter, \& Lean, 2006). As part of the WDC, the club losing the most weight received the WDC Trophy as recognition of their achievement in an important annual event, the District Rotary conference.

Although it was clearly evident that Champions had influenced the uptake of the program by their peers, the attributes that would make a Champion successful in a service club setting have yet to be explored. In this study, compared to the average Rotary club members, Champions were younger (55 vs. 59 years), more educated, still in the labour force, and held leadership positions in their clubs. They also believed that they could positively influence their peers and were fairly new to Rotary and hence had the energy to drive health programs, and they believed in the importance of health prevention. However, no measure or study has been developed to identify which specific characteristics or qualities LHAs need in health promotion in community settings to ensure the success of the intervention (Stahl \& Hill, 2008).. The research team is currently working on such a project.

While future research needs to explore the particular attributes of Champions that may impact on the successful uptake of community-based programs, the potential impact on the Champions and their peers of a sense of belonging to a community cannot be underestimated. Research evidence suggests that the context and social landscapes within which community campaigns operate contribute to outcomes as the characteristics of charismatic individuals do (McMillan, 1996; McMillan \& Chavis, 1986; Peterson, Speer, \& McMillan, 2008). Indeed there are strong social ties and networks that bind Rotarians within and between clubs and that may be a key factor in sustainability of health programs like the WDC. Although funding ceased in 2010, this project continued for eighteen months in clubs where Champions have not left their clubs. The service club setting has proved to be a supportive setting for health behaviour change and fostered socially supportive norms for health through a natural social network (Fleury, et al., 2009; Tessaro et al., 2000).

\section{Limitations}

The study used a non-randomised study design which was a compromise between a decrease in scientific rigour (efficacy) and an increase in reach and adoption. This intervention was applied in a real world community group, with people at high risk rather than a clinical group with a known disease, which makes it more challenging in terms of the five RE-AIM dimensions (Reach, Efficacy, Adoption, implementation, Maintenance) (Glasgow, McKay, Piette, \& Reynolds, 2001). In terms of where energies need to be directed in this field and implications for practice, Glasgow et al. (2001) recommended that "If we are to come close to eliminating health disparities or producing effective population-based chronic illness 
interventions, much greater attention will need to be paid to 'Reach' and 'Adoption' dimensions in the future". A future analysis of results will attempt a formal evaluation of the WDC in terms of the five dimensions of the RE-AIM framework.

Although the evaluation data were given anonymously, there could have been a bias in the favourable evaluations given by the clubs regarding the delivery of the presentations by the Champion being one of them. It would have been more rigorous if the project team, or an independent provider, had taken the height and weight measurements. However such community programs need to be owned and led by the lay members if they are to be cost effective, sustainable and with a wider applicability. It would have been extremely costly for the project team to travel to 52 clubs on a monthly basis for a year (624 visits), some clubs being eight hours drive from the university base. The uniformity of results across clubs proved that the training had worked well and the measurements were reliable. Quality assurance of data entered in the BMI competition was undertaken by the research team on a monthly basis.

There was no information collected on non-participants in the BMI competition, who could have been those with BMI less than 25 and did not see a need to take part. However as $70 \%$ of club members participated, we do not believe that BMI outcomes could be biased with such a large number participating.

\section{Conclusion}

This project demonstrated the role and influence of Champions in a lifestyle program for populations at risk of developing chronic diseases, thus potentially decreasing reliance on health professionals. This is particularly relevant where resources are stretched and where there are difficulties in recruiting trained health professionals. The project responded directly to key health organisations' imperatives to find new approaches to overcoming barriers and identifying motivators for sustaining healthy behaviour. Currently non-government organisations (NGOs) such as diabetes associations, national heart foundations and cancer councils are not able to reach this particular group through their regular programs. The findings provide an encouraging indication that community-based interventions for men at-risk of developing chronic disease are a feasible alternative to be adopted byprivate and public health services and NGO programs in partnerships with community organizations.

\section{Acknowledgements}

The Champions' Training Program of the 'Waist' Disposal Challenge was supported by funding from the Australian Department of Health and Ageing through the 'Sharing Health Care Initiative'. Authors acknowledge the contribution of the Rotary Champions in enriching the program and the four health educators who helped shape the content of the program: Fiona Collins, Stephanie McFaull, Dr Mike Newton and Jacquie Heron. 
Table 1: Change in knowledge and confidence of Champions

\begin{tabular}{|l|c|c|}
\hline$\%=$ Very good to good & $\begin{array}{c}\text { Pre-Training } \\
(\%)\end{array}$ & $\begin{array}{c}\text { Post-Training } \\
(\%)\end{array}$ \\
\hline Understanding Chronic Disease Self-Management & 28 & 90 \\
Understanding the 3 levels of WDC & 8 & 96 \\
Understanding the Champion's role & 23 & 98 \\
Confidence in motivating members & 53 & 80 \\
Understanding goal setting to help peers & 48 & 87 \\
Confidence to develop action plans & 51 & 79 \\
Confidence to run BMI Competition & 50 & 89 \\
Knowledge to encourage peers to improve nutrition & 32 & 78 \\
Knowledge to encourage peers to increase physical activity & 33 & 78 \\
Confidence to facilitate WDC in club & 57 & 86 \\
Confidence to present to club on nutrition or physical activity & 58 & 82 \\
\hline
\end{tabular}

*All p-values $<0.0001$; Response categories were: very good, good, moderate, poor, very poor.

\section{Table 2: Club Evaluations on Educational Presentations}

\begin{tabular}{|c|c|c|c|}
\hline $\begin{array}{l}\text { Overview Presentation } \\
\text { \# of Clubs: } 42 \\
\text { \# of Evaluations Received: } 346\end{array}$ & $\begin{array}{l}\text { Very } \\
\text { Much } \\
(\%)\end{array}$ & $\begin{array}{l}\text { Partially } \\
(\%)\end{array}$ & $\begin{array}{l}\text { Not at } \\
\text { All } \\
(\%)\end{array}$ \\
\hline $\begin{array}{l}\text { Did the presentation increase your awareness of risk factors } \\
\text { for chronic diseases? }\end{array}$ & 54 & 39 & 7 \\
\hline $\begin{array}{l}\text { Did the presentation increase your awareness of the } \\
\text { consequences of not keeping a healthy weight? }\end{array}$ & 62 & 32 & 6 \\
\hline $\begin{array}{l}\text { As a result of the presentation, are you now motivated to start } \\
\text { making changes to your lifestyle? }\end{array}$ & 56 & 40 & 4 \\
\hline $\begin{array}{l}\text { Nutrition Presentation } \\
\text { \# of Clubs: } 32 \\
\text { \# of Evaluations Received: } 323\end{array}$ & $\begin{array}{l}\text { Very } \\
\text { Much } \\
(\%)\end{array}$ & $\begin{array}{l}\text { Partially } \\
\text { (\%) }\end{array}$ & $\begin{array}{l}\text { Not at } \\
\text { All } \\
(\%)\end{array}$ \\
\hline $\begin{array}{l}\text { Did the presentation increase your awareness of what foods } \\
\text { are high in fat and kilojoules (calories)? }\end{array}$ & 55 & 43 & 2 \\
\hline $\begin{array}{l}\text { Did the presentation increase your awareness of what you can } \\
\text { do to lose weight? }\end{array}$ & 43 & 49 & 3 \\
\hline $\begin{array}{l}\text { As a result of the presentation, how motivated are you to make } \\
\text { changes to your diet? }\end{array}$ & 51 & 43 & 5 \\
\hline $\begin{array}{l}\text { Exercise Presentation } \\
\text { \# of Clubs: } 31 \\
\text { \# of Evaluations Received: } 290\end{array}$ & $\begin{array}{l}\text { Very } \\
\text { Much } \\
(\%)\end{array}$ & $\begin{array}{l}\text { Partially } \\
\text { (\%) }\end{array}$ & $\begin{array}{l}\text { Not at } \\
\text { All } \\
(\%)\end{array}$ \\
\hline $\begin{array}{l}\text { Did the presentation increase your awareness of what physical } \\
\text { activity can do for you? }\end{array}$ & 48 & 48 & 5 \\
\hline $\begin{array}{l}\text { Did the presentation increase your awareness of what you can } \\
\text { do to lose weight? }\end{array}$ & 43 & 46 & 5 \\
\hline $\begin{array}{l}\text { As a result of the presentation, how motivated are you to } \\
\text { increase your physical activity? }\end{array}$ & 56 & 41 & 3 \\
\hline
\end{tabular}


Table 3: Leaderboard of BMI Competition

\begin{tabular}{|c|c|c|c|c|c|c|c|c|}
\hline District & $\begin{array}{l}\text { Rotary } \\
\text { Club }\end{array}$ & Rank & $\begin{array}{l}\text { Number of } \\
\text { Participants }\end{array}$ & $\begin{array}{c}\text { Change } \\
\text { in BMI } \\
(\%)\end{array}$ & P-Value & \begin{tabular}{|c|} 
Members \\
with \\
Decreasing \\
Weight $(\%)$ \\
\end{tabular} & $\begin{array}{c}\text { Total } \\
\text { Weight } \\
\text { Change } \\
\text { (KG) }\end{array}$ & $\begin{array}{l}\text { Star } \\
\text { Loser } \\
\text { (KG) }\end{array}$ \\
\hline 9455 & $\mathrm{JN}$ & 1 & 12 & -3.06 & 0.005 & 91.67 & -31.5 & -6.1 \\
\hline 9455 & DA & 2 & 51 & -2.50 & 0.000 & 82.35 & -107.9 & -16.0 \\
\hline 9455 & BM & 3 & 19 & -2.18 & 0.011 & 68.42 & -40.2 & -13.1 \\
\hline 9455 & SU & 4 & 10 & -2.12 & 0.018 & 80.00 & -19.8 & -5.2 \\
\hline 9455 & GN & 5 & 17 & -2.10 & 0.033 & 76.47 & -33.8 & -12.0 \\
\hline 9465 & $\mathrm{KO}$ & 6 & 28 & -2.00 & 0.006 & 71.43 & -48.5 & -10.5 \\
\hline 9465 & SB & 7 & 34 & -1.96 & 0.078 & 50.00 & -59.2 & -27.3 \\
\hline 9465 & $\mathrm{FR}$ & 8 & 23 & -1.87 & 0.003 & 73.91 & -38.5 & -10.3 \\
\hline 9465 & $\mathrm{MJ}$ & 9 & 24 & -1.83 & 0.002 & 70.83 & -43.1 & -7.0 \\
\hline 9455 & FB & 10 & 9 & -1.76 & 0.025 & 77.78 & -14.8 & -5.1 \\
\hline 9465 & $\mathrm{BD}$ & 11 & 11 & -1.71 & 0.009 & 72.73 & -15.6 & -3.8 \\
\hline 9465 & $\mathrm{AP}$ & 12 & 17 & -1.70 & 0.004 & 70.59 & -25.9 & -4.4 \\
\hline 9465 & SP & 13 & 9 & -1.66 & 0.115 & 66.67 & -12.4 & -4.6 \\
\hline 9455 & GG & 14 & 42 & -1.54 & 0.006 & 73.81 & -61.5 & -13.4 \\
\hline 9465 & $\mathrm{PJ}$ & 15 & 21 & -1.20 & 0.006 & 76.19 & -22.6 & -3.9 \\
\hline 9455 & WN & 16 & 23 & -1.04 & 0.076 & 56.52 & -22.4 & -6.6 \\
\hline 9465 & $\mathrm{CM}$ & 17 & 22 & -0.98 & 0.139 & 40.91 & -17.7 & -6.9 \\
\hline 9455 & $M L$ & 18 & 27 & -0.89 & 0.011 & 37.04 & -23.2 & -5.5 \\
\hline 9455 & WP & 19 & 32 & -0.89 & 0.006 & 53.13 & -24.5 & -5.5 \\
\hline 9455 & DR & 20 & 10 & -0.77 & 0.182 & 50.00 & -6.0 & -2.4 \\
\hline 9465 & $\mathrm{KA}$ & 21 & 16 & -0.75 & 0.391 & 62.50 & -10.5 & -6.3 \\
\hline 9465 & VP & 22 & 20 & -0.67 & 0.207 & 30.00 & -12.9 & -8.0 \\
\hline 9465 & $A R$ & 23 & 14 & -0.65 & 0.017 & 50.00 & -8.0 & -2.0 \\
\hline 9465 & $A C$ & 24 & 28 & -0.57 & 0.207 & 60.71 & -14.1 & -5.7 \\
\hline 9465 & $\mathrm{KW}$ & 25 & 26 & -0.48 & 0.436 & 61.54 & -10.2 & -5.3 \\
\hline 9455 & $\mathrm{EP}$ & 26 & 16 & -0.46 & 0.499 & 56.25 & -5.1 & -3.3 \\
\hline 9455 & OP & 27 & 16 & -0.43 & 0.278 & 62.50 & -7.4 & -3.5 \\
\hline 9465 & MC & 28 & 24 & -0.40 & 0.476 & 45.83 & -10.2 & -7.6 \\
\hline 9465 & MA & 29 & 28 & -0.37 & 0.505 & 35.71 & -9.0 & -10.4 \\
\hline 9465 & $\mathrm{CO}$ & 30 & 29 & -0.35 & 0.351 & 48.28 & -9.1 & -4.7 \\
\hline 9455 & $\mathrm{HR}$ & 31 & 16 & -0.25 & 0.458 & 43.75 & -3.7 & -2.9 \\
\hline 9455 & MB & 32 & 11 & -0.19 & 0.559 & 36.36 & -2.0 & -2.0 \\
\hline 9455 & WY & 33 & 10 & -0.11 & 0.821 & 30.00 & -1.4 & -1.9 \\
\hline 9465 & AT & 34 & 28 & 0.09 & 0.787 & 46.43 & 1.7 & -2.5 \\
\hline 9465 & MV & 35 & 21 & 0.25 & 0.413 & 23.81 & 5.2 & -2.2 \\
\hline \multirow[t]{2}{*}{9455} & NO & 36 & 20 & 0.47 & 0.393 & 30.00 & 8.4 & -2.8 \\
\hline & Totals: & 36 & 764 & $-1.07 \%$ & & $57.59 \%$ & $-757.40 \mathrm{Kg}$ & \\
\hline
\end{tabular}

'Star loser' is the person who had lost most weight in a club 
Figure 1: The impact of the three levels of intervention on the cycle of behavioural change

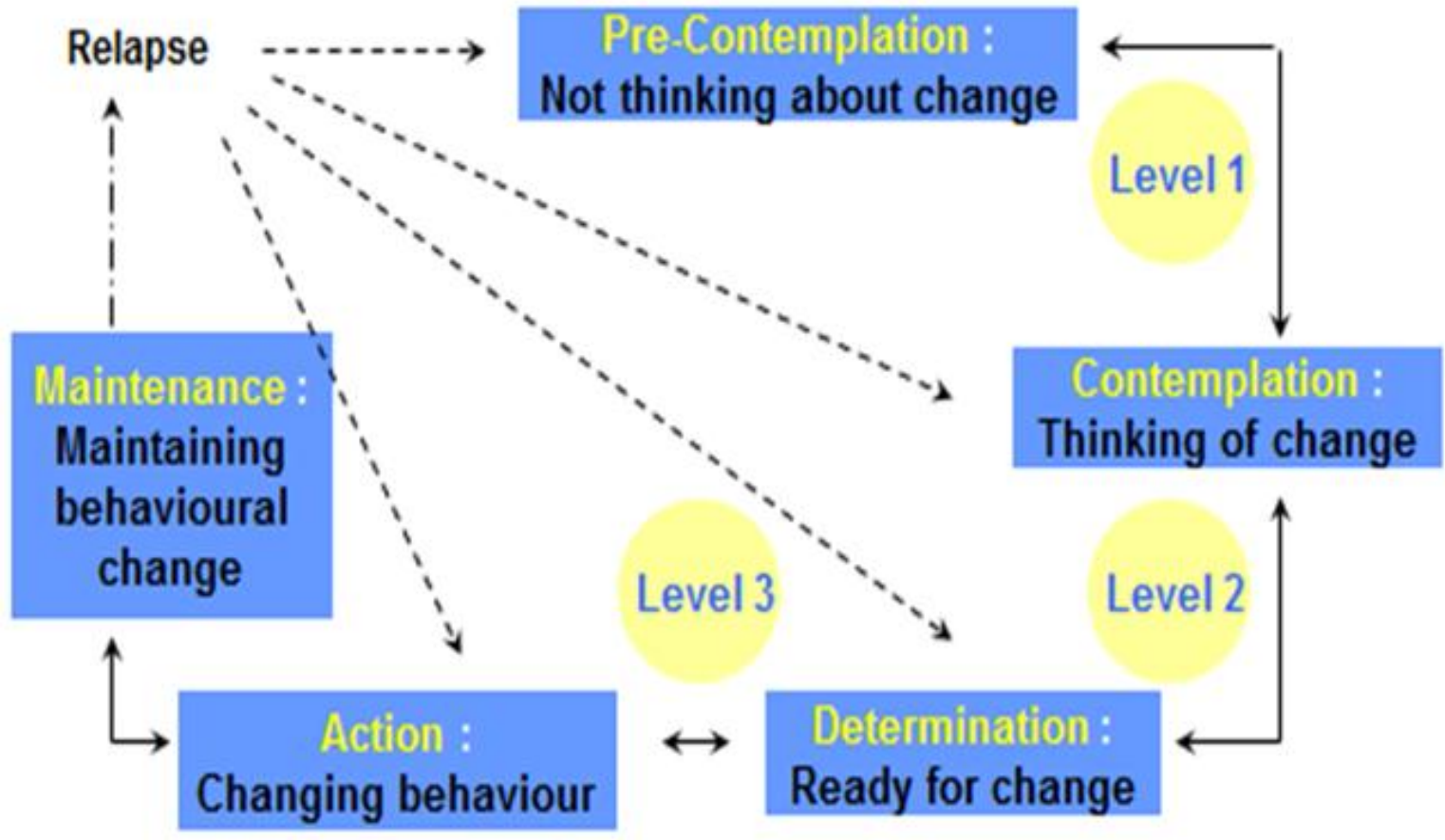

Figure 2: Average BMI of participating clubs per month

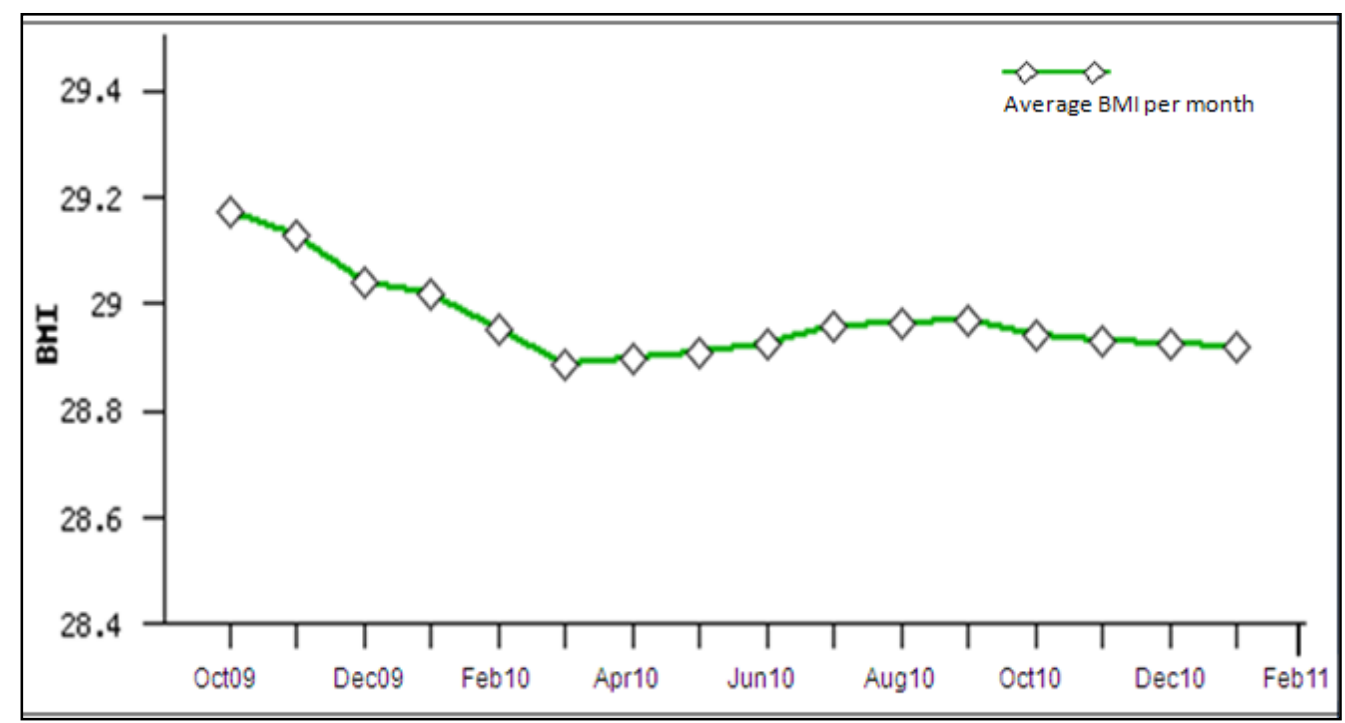




\section{REFERENCES}

Andrews, J. O., Felton, G., Wewers, M. E., \& Heath, J. (2004). Use of community health workers in research with ethnic minority women. Journal of Nursing Scholarship, 36(4), 358-365.

Aoun, S., Donovan, J. R., Johnson, L., \& Egger, G. (2002). Preventive care in the context of men's health. Journal of Health Psychology, 7(3), 243.

Aoun, S., \& Johnson, L. (2002). Men's health promotion by general practitioners in a workplace setting. Australian Journal of Rural Health, 10(6), 268-272.

Aoun, S., \& Le, L. (2010). Educating 'Champions' in Rotary Clubs to implement a community based self-management program "the 'Waist' Disposal Challenge”. Perth, Western Australia: WA Centre for Cancer and Palliative Care, Curtin University.

Aoun, S., Le, L., Osseiran-Moisson, R., \& Packer, T. (July 2009). Assessing the feasibility of the Rotary 'Waist' Disposal Project as a self-management community program to reduce obesity: Report on evaluation of the 'waist' disposal challenge. Perth, Western Australia: WA Centre for Cancer and Palliative Care, Curtin University.

Aoun, S., Osseiran-Moisson, R., Collins, F., Newton, R., \& Newton, M. (2009). A self-management concept for men at the community level: the 'Waist' Disposal Challenge. Journal of Health Psychology, 14(5), 663-674.

Aoun, S., Osseiran-Moisson, R., Shahid, S., Howat, P., \& O’Connor, M. (2011). Telephone Lifestyle Coaching Intervention for Men: is it feasible in a community service club setting? Journal of Health Psychology, 17(2):227-36. Epub 2011 Jul 8..

Avenell, A., Satter, N., \& Lean, M. (2006). Management: Part I - behaviour change, diet, and activity. BMJ, 333, 740-743.

Brown, C., Hennings, J., Caress, A.-L., \& Partridge, M. R. (2007). Lay educators in asthma self management: reflections on their training and experiences. Patient Education and Counseling, 68, 131-138.

Buckley, D., \& Lower, T. (2002). Factors influencing the utilisation of health services by rural men. Australian Health Review, 25(2), 11-15.

Campbell, M. K., Tessaro, I., DeVellis, B., Benedict, S., Kelsey, K., Belton, L., et al. (2002). Effects of a tailored health promotion program for female blue-collar workers: health works for women. Prev Med, 34(3), 313-323.

Commonwealth of Australia. (2008). Obesity in Australia, a need for urgent action. Canberra: Prepared for the National Preventative Health Taskforce by the Obesity Working Group. 
Daniels, K., Zyl H, H. V., Clarke, M., Dick, J., \& Johansson, E. (2005). Ear to the ground: listening to farm dwellers talk about the expereince of becoming lay health workers. Health Policy, 73, 92-103.

Debate, R. D., \& Plescia, M. (2004-2005). I could live other places, but this is where I want to be: support for natural helper initiatives. Int'l. Quarterly of Community Health Education, 23(4), 327-339.

Dhaliwal, S., Howat, P., Bejoy, T., \& Welborn, T. (2010). Self-reported weight and height for evaluating community obesity studies. American Journal of Health Behavior, 34(4), 489-499.

Eakin, E. G., Lawler, S. P., Vandelanotte, C., \& Owen, N. (2007). Telephone Interventions for Physical Activity and Dietary Behavior Change: A Systematic Review. American Journal of Preventive Medicine, 32(5), 419-434.

Egger, G. (2000). Intervening in men's nutrition: lessons from the GutBuster men's 'waist loss' program. Australian Journal of Nutrition and Dietetics, 57(1), 4649.

Eng, E., Rhodes, S. D., \& Parker, E. (2009). Natural helper models to enhance a community's health and competence. In R. J. DiClemente, R. A. Crosby \& M. Kegler (Eds.), Emerging theories in health promotion practice and research. Hoboken: Jossey-Bass.

Fleury, J., Keller, C., Perez, A., \& Lee, S. M. (2009). The role of lay health advisors in cardiovascular risk reduction: a review. Am J Community Psychol, 44(1-2), 28 42.

Foster, G., Taylor, S. J. C., Eldridge, S. E., Ramsay, J., \& Griffiths, C. J. (2008). Selfmanagement education programmes by lay leaders for people with chronic conditions The Cochrane Collaboration.

Glasgow, R. E., McKay, H. G., Piette, J. D., \& Reynolds, K. D. (2001). The RE-AIM framework for evaluating interventions: what can it tell us about approaches to chronic illness management? Patient Education and Counseling, 44(2), 119127.

Jackson, E. J., \& Parks, C. R. (1997). Recruitment and training issues from selected Lay Health Advisor programs among African Americans: A 20-year perspective. Health Education and Behaviour, 24(4), 418-431.

Knowles, M. (1984). The adult learner: A neglected species (3rd ed). Houston: Gulf Publishing Company.

Lorig, K. R., Hurwicz, M. L., Sobel, D., Hobbs, M., \& Ritter, P. L. (2005). A national dissemination of an evidence-based self-management program: a process evaluation study. Patient Educ Couns, 59(1), 69-79. 
McMillan, D. W. (1996). Sense of community. Journal of Community Psychology, 24(4), 315-325.

McMillan, D. W., \& Chavis, D. M. (1986). Sense of community: A definition and theory. Journal of Community Psychology, 14(1), 6-23.

Nutbeam, D., \& Harris, E. (1998). Theory in a Nutshell: A practitioner's guide to commonly used therories and models in health promotion. Sydney: National Center for Health Promotion.

O'Kane, G. M., Craig, P., Black, D., \& Sutherland, D. (2008). Riverina mens study: a preliminary exploration of the diet, alcohol use and physical activity behaviours and attitudes of rural men in two Australian New South Wales electorates. Rural and Remote Health, 8, 851-864.

Peterson, N. A., Speer, P. W., \& McMillan, D. W. (2008). Validation of a brief sense of community scale: confirmation of the principal theory of sense of community. Journal of Community Psychology, 36(1), 61-73.

Quinn, M. T., \& McNabb, W. L. (2001). Training lay health educators to conduct a church-based weight-loss program for African American women. Diabetes Educ, 27(2), 231-238.

Rhodes, S. D., Foley, K. L., Zometa, C. S., \& Bloom, F. R. (2007). Lay health advisor interventions among Hispanics/Latinos: a qualitative systematic review. Am J Prev Med, 33(5), 418-427.

Richert, M. L., Webb, A. J., Morse, N. A., O'Toole, M. L., \& Brownson, C. A. (2007). Move More Diabetes: using Lay Health Educators to support physical activity in a community-based chronic disease self-management program. Diabetes Educ, 33 Suppl 6, 179S-184S.

Rotary International. (2011). Service and Fellowship. from http://www.rotary.org/EN/SERVICEANDFELLOWSHIP/Pages/ridefault.aspx

Smith, J. A., Braunack-Mayer, A., \& Wittert, G. (2006). What do we know about men's help-seeking and health service use? MJA, 184(2), 81-83.

Stahl, J. V., \& Hill, C. E. (2008). A comparison of four methods for assessing natural helping ability. Journal of Community Psychology, 36(3), 289-298.

Tessaro, I. A., Taylor, S., Belton, L., Campbell, M. K., Benedict, S., Kelsey, K., et al. (2000). Adapting a natural (lay) helpers model of change for worksite health promotion for women. Health Educ Res, 15(5), 603-614.

VanWormer, J. J., \& Boucher, J. L. (2004). Motivational interviewing and diet modification: A review of the evidence. Diabetes Educator, 30(3), 404-419. 
Vissman, A. T., Eng, E., Aronson, R. E., Bloom, F. R., Leichliter, J. S., Montano, J., et al. (2009). What do men who serve as lay health advisers really do?: Immigrant Latino men share their experiences as Navegantes to prevent HIV. AIDS Educ Prev, 21(3), 220-232.

Zimmerman, G. L., Olsen, C. G., \& Bosworth, M. F. (2000). A 'stages of change' approach to helping patients change behavior. American Family Physician, 61(5), 1409-1416. 